\title{
Cytomegalovirus infection associated with ulcerative colitis in immunocompetent individuals
}

\author{
Carmit Rachima, Eran Maoz, Sara Apter, Michael Thaler, Ehud Grossman, \\ Talma Rosenthal
}

\begin{abstract}
Summary
Gastrointestinal infection with cytomegalovirus (CMV) is usually found in immunocompromised patients and rarely affects immunocompetent subjects. We describe two immunocompetent patients who had primary CMV infection, and in both the disease was associated with ulcerative colitis. Both patients recovered from the CMV infection spontaneously.
\end{abstract}

Keywords: cytomegalovirus infection; ulcerative colitis; immunocompetent subjects

Cytomegalovirus (CMV) is recognised as an important pathogen with a worldwide distribution. Gastrointestinal infections with CMV, especially colitis, are usually found in immunocompromised patients and rarely affect immunocompetent subjects. ${ }^{1-9}$ CMV infection has also been related to inflammatory bowel disease (IBD), either as a precipitating factor or as a coincidental infection. ${ }^{10-15}$

We report two cases of immunocompetent patients with primary $\mathrm{CMV}$ infections. In the first case acute CMV infection was associated with exacerbation of IBD, and in the second case CMV infection coincided with the onset, and led to the diagnosis of IBD. Both patients recovered from the CMV infection spontaneously.

\section{Case reports}

Case 1

A 38-year-old woman was hospitalised because of spiking fever, dyspnoea, abdominal pain, and non-bloody diarrhoea. Eight years earlier she had been diagnosed as having ulcerative colitis; she was treated with a short course of steroids and had remained symptom-free ever since. Thirteen weeks prior to admission she had an uneventful childbirth. Seven weeks later she developed a febrile illness with watery diarrhoea. Stool cultures were positive for Shigella mansoni, and she was treated successfully with amoxycillin. Two weeks before admission she again developed fever up to $39.7^{\circ} \mathrm{C}$, chills, weakness, dyspnoea, abdominal pain and watery diarrhoea.

Physical examination revealed an ill-looking woman with a blood pressure of $90 / 60 \mathrm{mmHg}$, pulse rate of 104 beats/min, and a temperature of $39^{\circ} \mathrm{C}$. No lymphadenopathy was noted. Cardiac examination was normal, and decreased breathing sounds were heard over the right lung base. Abdominal examination re- vealed an enlarged liver $2 \mathrm{~cm}$ below the costal margin, with a rebound tenderness over the right upper quadrant.

Laboratory investigations revealed leucocytosis of $33.1 \times 10^{9} / 1$ with $59 \%$ polymorphonucleocytes, and $33 \%$ lymphocytes with atypical forms. Haemoglobin was $11.6 \mathrm{~g} / \mathrm{dl}$ with normal platelet count. Other laboratory studies were normal except for an elevated alkaline phosphatase $(262 \mathrm{IU} / 1$, normal $<115 \mathrm{IU} / \mathrm{l})$ and lactate dehydrogenase (464 IU/l, normal $<250$ IU/1). Chest X-ray showed bilateral lung infiltrates. Electrocardiogram was normal except for sinus tachycardia.

On the second day of hospitalisation she became dyspnoeic and hypoxemic with a temperature of $39.6^{\circ} \mathrm{C}$ and severe abdominal pain mainly in the right upper quadrant. Physical examination noted guarding on the right upper quadrant, suggesting peritoneal inflammation. HIDA $\left(9^{\mathrm{m}} \mathrm{Tc}\right.$-labeled $\mathrm{N}$-substituted immunodiacetic acid) biliary scan findings were consistent with the diagnosis of cholecystitis, and intravenous antibiotics were started. Blood, urine and stool cultures remained sterile. Abdominal computed tomography (CT) scan showed thickening of the gallbladder wall as well as thickening of the colonic wall without evidence of lymphadenopathy (figure 1). Serologic tests for hepatitis $B$ and $C$, human immunodeficiency (HIV), and Epstein Barr viruses were negative. Solid-phase enzyme immunoassay for IgM antibodies to CMV was highly positive $(3+)$ on admission and decreased to (1+) over time. ${ }^{16}$ Immunofluorescence assay for IgG antibodies to CMV showed a titre of $1: 160$ on admission and increased to $1: 320$ later. ${ }^{17}$ Subsequently, CMV was detected in the urine by polymerase chain reaction and the Shell vial assay. ${ }^{18}$

Sigmoidoscopy up to $40 \mathrm{~cm}$ revealed oedematous, inflamed mucosa with fibrinopurulent exudate and small haemorrhages. Mucosal biopsy specimens demonstrated acute and chronic inflammatory process with crypt abscess. CMV inclusion bodies were not identified, and CMV was not detected by immunoperoxidase staining.

During the first 3 weeks the patient had a temperature of $38-40^{\circ} \mathrm{C}$ and severe watery diarrhoea. Blood counts were notable for marked leucocytosis $\left(20-30 \times 10^{9} / 1\right)$ with $30-40 \%$ lymphocytes and marked thrombocytosis (up to $\left.1000 \times 10^{9} / 1\right)$. In addition, signs of malabsorption developed with hypoalbuminaemia of $2 \mathrm{~g} / \mathrm{dl}$ and hypocholesterolaemia of $58 \mathrm{mg} / \mathrm{dl}$. 
Figure 1 Abdominal CT scan showing (A) thickening of the gallbladder wall (arrow), (B) thickening of the colonic wall (arrow)
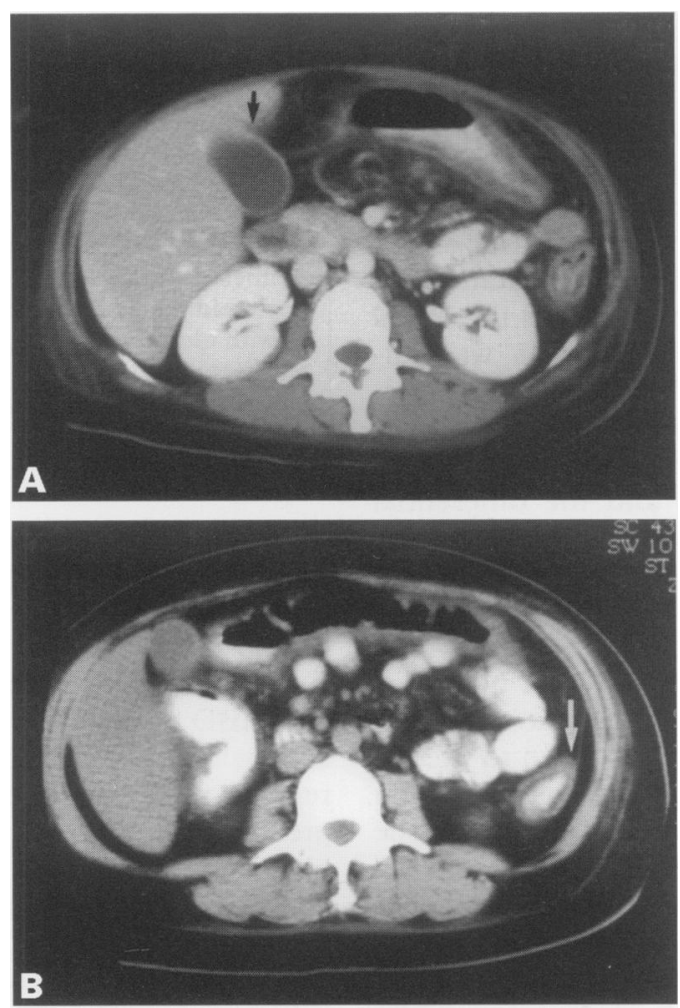

The colonic findings were compatible with exacerbation of ulcerative colitis and she was treated with 5 -aminosalicylic acid ( $2 \mathrm{~g} /$ day). $\mathrm{Her}$ symptoms resolved completely after 2 months of treatment with no antiviral therapy or steroids.

Case 2

A 20-year-old man, who had a history of bronchial asthma and had undergone splenec-

Figure 2 CT scans showing (A) thickened wall of the colon (arrow), (B) thickened wall of the caecum (long arrow), and peritoneal fluid (short arrow) tomy and cholecystectomy at the age 12 years because of congenital spherocytosis, was hospitalised with a febrile illness. His medications included amoxycillin, which he had been taking prophylactically since the splenectomy, and inhaled steroids during exacerbation of his asthma. Four days before admission, he developed a fever of $39.5^{\circ} \mathrm{C}$ with diffuse abdominal pain and a nonproductive cough. On admission, he had a temperature of $38.2^{\circ} \mathrm{C}$, pulse rate of 88 beats/min, and blood pressure of $110 / 60 \mathrm{mmHg}$. The physical examination was otherwise unremarkable. Laboratory investigations were normal except for a leucocytosis of $12.7 \times 10^{9} / 1$, an elevated bilirubin level of $34.2 \mu \mathrm{mol} / 1$ and an elevated lactate dehydrogenase up to $300 \mathrm{IU} / 1$. Because of his history of splenectomy he was given amoxycillin clavulonate.

During the first 2 weeks of hospitalisation, abdominal pain was localised in the right lower quadrant and was associated with fever of $38-40^{\circ} \mathrm{C}$, chills and abdominal guarding suggesting peritoneal signs. Laboratory evaluation showed a marked leucocytosis of up to $33 \times$ $10^{\circ} / 1$ with $58 \%$ lymphocytes and abnormal liver function tests (bilirubin 15.4-56.4 $\mu \mathrm{mol} / \mathrm{l}$, lactate dehydrogenase 359-642 IU/1, aspartate transaminase 335-397 IU/1, alanine transaminase 332-360 IU/1). Repeated blood, urine and stool cultures were negative. Chest and abdominal CT scans showed marked colonic wall thickening with a small amount of peritoneal fluid (figure 2). Gallium scan showed increased isotope concentration in the right lower abdomen and over the lungs.

After 2 weeks of observation, spontaneous clinical and laboratory improvement was observed. Serological tests for hepatitis A, B and $C$ viruses, and HIV were negative. Solid-phase enzyme immunoassay for IgM antibodies to CMV was highly positive $(3+)$ on admission and decreased to $(1+)$ over time. Immunofluorescence assay for IgG antibodies to CMV showed a titre of $1: 160$ on admission and had increased to 1:320 2 months later.

Three weeks later he again developed fever associated with mucoid and bloody diarrhoea. Blood, urine and stool cultures were negative. His blood count was normal except for a leucocytosis of $17.8 \times 10^{9} / 1$ with $43 \%$ lymphocytes. Sigmoidoscopy showed evidence of an inflammatory process, and mucosal biopsy demonstrated an inflammatory process with crypt abscess; CMV inclusion bodies were not identified and CMV was not detected by immunoperoxidase staining. A diagnosis of ulcerative colitis was made and treatment with metronidazole and 5-aminosalicylic acid was initiated. A month later his clinical condition had improved, and during a follow-up period of 3 years he fully recovered from the CMV infection but had repeated bouts of colitis.

\section{Discussion}

CMV can affect many organs including the lungs, retina, liver, and gastrointestinal tract. ${ }^{19}$ Gastrointestinal tract disease may involve the mouth, oesophagus, stomach, small intestine and colon. ${ }^{19} \mathrm{CMV}$ colitis is a major cause of 
morbidity and mortality in immunocompromised patients but less so in immunocompetent individuals. ${ }^{20} \mathrm{CMV}$ colitis produces mucosal ulceration that can result in abdominal pain, bloody diarrhoea and even perforation, a clinical picture that resembles IBD. ${ }^{21-23}$ Surawitz and Myerson ${ }^{21}$ described three cases of isolated CMV colitis with a presentation of haematochezia. In all three patients the initial differential diagnosis of the colitis was idiopathic IBD but colonic biopsies showed typical CMV inclusion bodies without any other histological features of IBD. The radiographic findings are not specific and the differential diagnosis includes granulomatous ileocolitis and ulcerative colitis. ${ }^{24}$

The link between IBD and CMV infection is unclear. Our immunocompetent individuals had CMV infection associated with ulcerative colitis. Although, the second patient had a previous splenectomy this is not known to predispose to viral infection. The first patient had a history of inactive ulcerative colitis when she presented with CMV infection. In her case the CMV infection was associated with exacerbation of silent ulcerative colitis. Several case reports have described CMV colitis in patients with IBD. ${ }^{10} 11{ }^{23}{ }^{25-30}$ In all these cases CMV inclusion bodies were detected in the colonic mucosa. Indeed, the possibility that acute CMV colitis mimics IBD cannot be excluded, however the absence of CMV inclusion bodies in mucosal biopsies make this unlikely. It has been shown that patients with ulcerative colitis are more likely to show elevated titres to CMV than normal subjects. ${ }^{14-15}$ Moreover, it has been suggested that resistant ulcerative colitis that requires colectomy may be related to $\mathrm{CMV}$ infection. Indeed, Cooper et $a l^{11}$ described CMV inclusion bodies in a subgroup of patients with ulcerative colitis who underwent partial colectomy.

Our second patient had no history of ulcerative colitis. In his case CMV infection coincided with the onset, and led to the diagnosis, of acute ulcerative colitis. Although he recovered from the acute $\mathrm{CMV}$ infection he has

1 Drew WL, Mintz L, Miner RC, Sands M, Ketterer B Prevalence of cytomegalovirus infection in homosexual men. F Infect Dis 1981;143:188-92.

2 Gertler SL, Pressman J, Price P, Brozinsky S, Miyai K. Gastrointestinal cytomegalovirus infection in homosexual men with severe acquired immunodeficiency syndrome. Gastrowith severe acquired immu

3 Quinnan GV Jr, Masur H, Rook AH, et al. Herpesvirus Quinnan GV Jr, Masur $\mathrm{H}$, Rook AH, et al. Herpesvirus infections in the acquired

4 Schooley RT. Cytomegalovirus in the setting of infection with human immunodeficiency virus. Rev Infect Dis 1990;12:S811-9.

5 Spencer GD, Hackman RC, McDonald GB, et al. A prospective study of unexplained nausea and vomitin after marrow transplantation. Transplantation 1986;42:6027.

6 Rubin RH. Impact of cytomegalovirus infection on organ transplantation recipients. Rev Infect Dis 1990;12:s754-66.

7 Orioff J, Saito R, Lasky S, Dave H. Toxic megacolon in cytomegalovirus colitis. Am $\mathcal{F}$ Gastroenterol 1989;84: 794-7.

8 Henson D. Cytomegalovirus inclusion bodies in the gastrointestinal tract. Arch Pathol 1972;93:477-82.

9 Ayulo M, Aisner SC, Margolis K, Moravec C. Cytomegalovirus associated gastritis in a compromised host. $¥ A M A$ virus associated gast

10 Berk T, Gordon SJ, Choi HY, Cooper HS. Cytomegalovirus infection of the colon: a possible role in exacerbation of inflammatory bowel disease. Am $\mathcal{F}$ Gastroenterol 1985;80 355-60.

\section{Summary points}

- CMV infection may be associated with ulcerative colitis

- CMV infection associated with ulcerative colitis may occur in immunocompetent patients

- ulcerative colitis may recover when CMV infection improves

- steroid therapy is not recommended in patients with ulcerative colitis associated with CMV infection

had relapses of the ulcerative colitis. Orvar $e t a l^{12}$ described two patients in whom the primary CMV infections coincided with the onset and diagnosis of ulcerative colitis. It has been suggested that primary CMV infection precipitated IBD by enhancing surface antigen marker expression in a host predisposed to IBD. ${ }^{12}$ It remains uncertain whether CMV merely has a predilection for inflamed mucosa or actually plays a role in the pathogenic process.

The association of CMV infection and ulcerative colitis raises the problem of whether or not steroids should be used. It has been shown in patients with severe ulcerative colitis, who were resistant to steroid therapy, and had CMV inclusion bodies in the mucosa, that steroid withdrawal led to a clinical and histological improvement. ${ }^{10-29}$ It seems that cessation of corticosteroids enables the patient to overcome the CMV infection. A similar mechanism was described for chronic hepatitis $B$ virus, in which immunosuppressive drugs were shown to enhance viral replication, while cessation of these drugs decrease its replication. ${ }^{31}{ }^{32}$ The controversy remains as to whether steroids or immunosuppressive drugs can cause CMV superinfection with IBD exacerbation. It is noteworthy that our patients recovered from the ulcerative colitis without steroid therapy when the CMV infection improved. Thus, steroid therapy should be used with caution in patients with ulcerative colitis associated with $\mathrm{CMV}$ infections.

11 Cooper HS, Raffensper EC, Jonas L, Fitts WT. Cytomegalovirus inclusions in patients with ulcerative colitis and toxic dilatation requiring colonic resection. Gastroenterology 1977 ; 72:1253-6.

12 Orvar K, Murray J, Carmen G, Conklin J. Cytomegalovirus infection associated with onset of inflammatory bowel infection associated with onset of in

13 Diepersloot RJA, Kroes ACM, Visser W, Jiwa NM Rothbarth PH. Acute ulcerative proctocolitis associated with primary cytomegalovirus infection. Arch Intern Med 1990;150:1749-51.

14 Farmer GW, Vincent MM, Fuccillo DA, et al. Viral investigations in ulcerative colitis and regional enteritis. Gastroenterology 1973;65:8-18.

15 Bernades P. Antibodies to cytomegalovirus in ulcerative colitis and Crohn's disease. Gastroenterol Clin Biol 1980;4:128-33.

16 Schmitz H, Doerr HW, Kampa D, Vogt A. Solid-phase enzyme immunoassay for immunoglobulin $M$ antibodies to cytomegalovirus. F Clin Microbiol 1977;5:629-34.

17 Phipps PH, Gregoire L, Rossier E, Perry E. Comparison of five methods of cytomegalovirus antibody screening of blood donors. f Clin Microbiol 1983;18:1296-300.

18 Miller MJ, Bovey S, Pado K, Bruckner DA, Wagar EA. Application of PCR to multiple specimen types for diagnosis of cytomegalovirus infection: Comparison with cell culture and shell vial assay. $\mathcal{F}$ Clin Microbiol 1994;32:5-10.

19 Goodgame RW. Gastrointestinal cytomegalovirus disease. Ann Intern Med. 1993;119:924-35.

20 Buckner FS, Pomeroy C. Cytomegalovirus disease of the gastrointestinal tract in patients without AIDS. Clin Infect Dis 1993;17:644-56. 
21 Surawitz CM, Myerson D. Self-limited cytomegalovirus colitis in immunocompetent individuals. Gastroenterolog 1988;94:194-9.

22 Cunningham $\dot{M}$, Cantoni L, Humair L. Cytomegalovirus primoinfection in a patient with idiopathic proctitis. $A m \mathcal{F}$ Gastroenterol 1986;81:586-8.

23 Guttman D, Raymond A, Gelb A, Ehya H, Mather V, Mildvan $D$, et al. Virus-associated colitis in homosexual men: two van $\mathrm{D}$, et al. Virus-associated colitis in homosexual

24 Balthazar EJ, Megibow AJ, Fazzini E, Opulencia J, Engel I. Cytomegalovirus colitis in AIDS: Radiographic findings in Cytomegalovirus colitis in AIDS: Radiog
11 patients. Radiology 1985;155:585-9.

25 Powell RD, Warner NE, Levine RS, et al. Cytomegalic inclusion disease and ulcerative colitis. Report of a case in a young adult. $A m \mathcal{F}$ Med 1961;30:334-40.

26 Wong TW, Warner NE. Cytomegalic inclusion disease in adults. Report of 14 cases with review of the literature. Arch Pathol. 1962;74:403-22.
27 Levine RS, Warner NE, Johnson CF. Cytomegalic inclusion disease in the gastrointestinal tract of adults.Ann Surg 1964 159:37-48.

28 Keren DF, Milligan FD, Strandberg JD, Yardley JH. Intercurrent cytomegalovirus colitis in a patient with ulcerative colitis. Fohns Hopkins Med f 1975;136:178-82.

29 Dent DM, Duys PJ, Bird AR, et al. Cytomegalovirus infection of the bowel in adults. $S$ Afr Med $\mathcal{f} 1975 ; 49: 669-$ infectic

30 Sidi S, Graham JH, Razvi SA, et al. Cytomegalovirus infecSidi S, Graham JH, Razvi SA, et al. Cytomegalovirus infec-
tion of the colon associated with ulcerative colitis. Arch Surg

31 Swarbrick ET, Kingham JGC, Price HL, et al. Chlamydia, cytomegalovirus and Yersinia in inflammatory bowel disease. Lancet 1979;2:11-2.

32 Scullard GH, Smith CI, Merigan TC, et al. Effects of immunosuppressive therapy on viral markers in chronic active hepatitis B. Gastroenterology 1981;81:987-91.

\title{
Familial cavernous angiomas masquerading as multiple sclerosis
}

\section{Royal Victoria Infirmary, Queen Victoria Road, \\ Newcastle upon Tyne NE1 4LP, UK \\ Department of \\ Neurology \\ C F Dougan \\ N E F Cartlidge \\ D J Burn \\ Department of \\ Radiology \\ A Coulthard \\ Correspondence to \\ Dr DJ Burn}

Accepted 10 March 1998

\author{
C F Dougan, A Coulthard, N E F Cartlidge, D J Burn
}

\begin{abstract}
Summary
We report here two cases of cavernous angioma, in the proband and her father, with quite different clinical presentations. The proband presented with a brainstem syndrome, mimicking multiple sclerosis, while the father had a history of mild epilepsy. Both patients were managed conservatively. The cases also demonstrate the utility of magnetic resonance imaging in the diagnosis of cavernous angioma.
\end{abstract}

Keywords: cavernous angiomas; multiple sclerosis; magnetic resonance imaging

Cavernous angiomas (also known as cavernomas and cavernous haemangiomas) are a form of intracranial vascular malformation that are reported to affect $0.5 \%$ of the population. ${ }^{1}$ In up to $75 \%$ of patients the lesions are multiple. They are characterised by collections of large, abnormal vascular spaces without intervening brain parenchyma. ${ }^{2} \mathrm{Up}$ to $50 \%$ of patients with cavernous angiomas have a familial form of the disorder which is inherited in an autosomal dominant mode, with incomplete clinical penetrance. ${ }^{1}$ The familial form may be more frequent in the Hispanic population. ${ }^{3}$ Recent genetic studies have identified linkage of this trait to chromosome 7q11.2-q21 in some families. ${ }^{12}$ Although cavernous angiomas are rarely life-threatening, they may cause significant morbidity related to their size and location.

\section{Case reports}

Case 1

A 19-year-old, right-handed woman was admitted in 1988 with a 5-day history of progressive neurological dysfunction. At the onset she had awoken with numbness of the left side of her tongue, which spread over 24 hours to affect the whole left side of her face. She sub- sequently developed horizontal diplopia, worse on right lateral gaze, and incoordination, with a tendency to fall to the left. On the day prior to admission she had developed patchy sensory disturbance in her left arm and leg. Her medical history was unremarkable. She was taking the oral contraceptive pill. She was one of four siblings and her father had epilepsy.

On general medical examination the only findings of note were haemangiomatous lesions on the dorsum of her left hand, left calf and right thigh. Neurologically, her gait was ataxic. Fundoscopy was normal, but there were bilateral partial sixth nerve palsies, and upbeat nystagmus on upgaze. There was a left sensory trigeminal neuropathy and mild subjective blunting of hearing on the left side. In the limbs there was a mild left-sided pyramidal weakness, with subjective reduction of light touch and pin-prick distally in the left arm and leg. A diagnosis of demyelination was suspected. Visual evoked potentials were normal. A computed tomography (CT) scan of the cranium revealed two small high-density lesions in the right side of the brainstem and left putamen, thought to represent areas of haemorrhage. Cerebrospinal fluid (CSF) examination was entirely normal, with absent oligoclonal bands. The patient's condition spontaneously improved, and follow-up CT brain scan 2 weeks later showed considerable resolution of the high density lesions.

Eight months later she was re-admitted with a relapse comprising similar brainstem symptoms and signs, following a minor acute neck sprain. Cranial magnetic resonance imaging (MRI) scan revealed three separate lesions typical of cavernous angiomas, including a large lesion in the tegmentum of the midbrain, eccentrically located to the right (figure).

The patient has been managed conservatively to date. She has suffered a number of relapses referable to the brainstem cavernous angioma but has recovered to normal 